This item was submitted to Loughborough's Research Repository by the author.

Items in Figshare are protected by copyright, with all rights reserved, unless otherwise indicated.

\title{
Risk and safety perception on urban and rural roads: effects of environmental features, driver age and risk sensitivity
}

PLEASE CITE THE PUBLISHED VERSION

http://dx.doi.org/10.1080/15389588.2017.1296956

PUBLISHER

(c) Taylor \& Francis

\section{VERSION}

AM (Accepted Manuscript)

\section{PUBLISHER STATEMENT}

This work is made available according to the conditions of the Creative Commons Attribution-NonCommercialNoDerivatives 4.0 International (CC BY-NC-ND 4.0) licence. Full details of this licence are available at: https://creativecommons.org/licenses/by-nc-nd/4.0/

\section{LICENCE}

CC BY-NC-ND 4.0

\section{REPOSITORY RECORD}

Cox, Jolene A., Vanessa Beanland, and Ashleigh Filtness. 2019. "Risk and Safety Perception on Urban and Rural Roads: Effects of Environmental Features, Driver Age and Risk Sensitivity”. figshare. https://hdl.handle.net/2134/24392. 
Risk and safety perception on urban and rural roads:

Effects of environmental features, driver age and risk sensitivity

Jolene A. Cox ${ }^{1}$, Vanessa Beanland ${ }^{2, *}$ and Ashleigh J. Filtness ${ }^{3,4}$

${ }^{1}$ Research School of Psychology, The Australian National University, Canberra, ACT 2601, Australia

${ }^{2}$ Centre for Human Factors and Sociotechnical Systems, University of the Sunshine Coast, Maroochydore DC, QLD 4558, Australia

${ }^{3}$ Centre for Accident Research and Road Safety - Queensland, Queensland University of Technology, Kelvin Grove, QLD 4059, Australia

${ }^{4}$ Loughborough Design School, Loughborough University, LE11 3TU, United Kingdom

* Corresponding author. Email: vbeanlan@usc.edu.au

\section{ACKNOWLEDGEMENTS}

This research was supported by a grant from the NRMA-ACT Road Safety Trust. Vanessa Beanland is supported by an Australian Research Council Discovery Early Career Researcher Award (DE150100083). We thank Shannon Webb and Erin Walsh for their assistance with photographing and editing the stimulus images. 


\section{ABSTRACT}

Objective: The ability to detect changing visual information is a vital component of safe driving. In addition to detecting changing visual information, drivers must also interpret its relevance to safety. Environmental changes considered to have high safety relevance will likely demand greater attention and more timely responses than those considered to have lower safety relevance. The aim of the present study was to explore factors that are likely to influence perceptions of risk and safety regarding changing visual information in the driving environment. Factors explored were the environment in which the change occurs (i.e., urban versus rural), the type of object that changes, and the driver's age, experience and risk sensitivity.

Methods: 63 licensed drivers aged 18-70 years completed a hazard rating task, which required them to rate the perceived hazardousness of changing specific elements within urban and rural driving environments. Three attributes of potential hazards were systematically manipulated: the environment (urban, rural); the type of object changed (road sign, car, motorcycle, pedestrian, traffic light, animal, tree); and its inherent safety risk (low-risk, high-risk). Inherent safety risk was manipulated by either varying the object's placement, on/near or away from the road, or altering an infrastructure element which would require a change to driver behaviour. Participants also completed two driving-related risk perception tasks, rating their relative crash risk and perceived risk of aberrant driving behaviours.

Results: Driver age was not significantly associated with hazard ratings, but individual differences in perceived risk of aberrant driving behaviours predicted hazard ratings, suggesting that general driving-related risk sensitivity plays a strong role in safety perception. In both urban and rural scenes there were significant associations between hazard ratings and inherent safety risk, with low-risk changes perceived as consistently less hazardous than high-risk impact changes; however, the effect was larger for urban environments. There were also effects of object type, with certain objects rated as consistently more safety relevant. In urban scenes, changes involving pedestrians were rated significantly more hazardous than all other objects, and in rural scenes, changes involving animals were rated as significantly more hazardous. Notably, hazard ratings were found to be higher in urban compared with rural driving environments, even when changes were matched between environments.

Conclusion: The present study demonstrates that drivers perceive rural roads as less risky than urban roads, even when similar scenarios occur in both environments. Age did not affect hazard ratings. Instead, the findings suggest that the assessment of risk posed by hazards is influenced more by individual differences in risk sensitivity. This highlights the need for driver education to account for appraisal of hazards' risk and relevance, in addition to hazard detection, when considering factors which promote road safety.

Key words: risk perception; risk sensitivity; safety perception; rural roads; urban roads 


\section{INTRODUCTION}

Road crashes are a leading cause of injury and death worldwide (WHO 2015), but individuals' crash risk varies according to several factors. For example, younger and older drivers are overrepresented in crash statistics (BITRE 2016). Crashes are also more severe and more common, based on population and kilometres travelled, in rural areas compared with urban areas (Siskind et al. 2011). These patterns suggest the relative safety of driving covaries with driver age and environment.

One factor that may contribute to differences in crash rates is subjective risk perception. Evaluation of relative risk involves judging the likelihood that harm will result from an action (Lowrance 1976). If apparent risks are acceptable (perceived safety), the individual may engage in risk-taking or fail to avoid hazards. Supporting the subjectivity of perceived safety, studies have found discrepancies between actual and perceived risk in driving situations (Charlton et al. 2014). Although some view risk perception as binary (safe/unsafe), recent research has advocated conceptualising it as a continuum (i.e., high-low; Gill 2004). Risk perception is a multivalent construct, influenced by life experiences, personality and attitudes (Beirness 1993; Kington et al. 1994; Vivoli et al. 2006). Individual differences play a crucial role, with great variability in overall risk sensitivity, which refers to consistent levels of risk perception across varied situations and risk domains (Sjöberg 2000).

\section{Environmental Differences in Risk Perception}

Differences in risk perception between environments could explain why serious crashes are often more common in rural areas (Eiksund 2009; NHTSA 2010; Nordjærn et al. 2010; Siskind et al. 2011). On rural roads drivers perceive high travel speeds as less risky due to higher speed limits and lower visual complexity (Rakauskas et al. 2009). The reduced visual clutter in rural settings can induce boredom and fatigue (Thiffault and Bergeron 2003) and may facilitate inappropriate visual scanning strategies, which affects hazard detection (Crundall and Underwood 1998). Moreover, drivers often neglect unsafe features of rural roads, such as road curvature, roadside ditches and poles (Charlton et al. 2014).

Overall, it appears that rural driving conditions foster a sense of complacency, prompting greater risktaking (Wilde 1998). Consistent with this, rural drivers are more likely to self-report aberrant behaviour and perceive these behaviours as less risky (Knight et al. 2013; Rakauskas et al. 2009). For example, young rural drivers consider speeding on rural roads an acceptable, controllable risk (Knight et al. 2013). However, most studies comparing risk perception between urban and rural environments have used between-subject comparisons (Dunsire and Baldwin 1999; Leadbeater et al. 2008; Nordjærn et al. 2010), effectively comparing rural and urban drivers, rather than environments. Within-subject comparisons of urban and rural driving environments are therefore required to provide more sensitive analysis (Streff and Geller 1988). Previous research examining within-subjects comparisons in risk perception has found that drivers identify different types of hazards in different environments (Borowsky and Oron-Gilad 2013) and that they rate situations with more information to process (e.g., cluttered scenes) as more hazardous (Benda and Hoyos 1983).

\section{Age-related Differences in Risk Perception}

Even when faced with an identical risk scenario, risk appraisal differs between individuals (Machado-León et al. 2016). Age and driving experience, which are usually highly correlated (Elander et al. 1993), can play a role 
(Finn and Bragg 1986). There is a curvilinear relationship between age and crash risk, with both younger and older drivers exhibiting elevated crash risk (BITRE 2016; Mayhew et al. 2003; Williams 2003). However, nature of crashes and underlying causes differs between younger and older drivers (Elander et al., 1993).

Among young novice drivers, hazard perception training leads to greater speed reductions and less risk taking (Crundall et al. 2010; Fisher et al. 2002; McKenna et al. 2006; Wang et al. 2010). This suggests that young drivers' elevated crash risk is partly attributable to ignorance; their inexperience limits their ability to appraise hazardous driving situations (Borowsky et al. 2009, 2010). This may be because less experienced drivers focus on isolated details within the scene, whereas more experienced make global evaluations of the broader driving environment (Benda and Hoyos 1983). To improve young driver safety, many jurisdictions including Australia have adopted graduated licensing systems (GLS), which aim to mitigate crash risk by applying restrictions that reduce exposure to high-risk situations during the first few years of driving. Further, many jurisdictions incorporate hazard perception testing within GLS, as hazard perception performance correlates with crash involvement (Boufous et al. 2011). Although GLS improves safety, young novice drivers still exhibit elevated crash rates and greater risk-taking (Lam 2003; Lewis-Evans 2010). As such, in a task evaluating drivers' assessment of hazards, it is likely that younger, less experienced drivers would show lower ratings, as they do not yet have sufficient appreciation of the potential risks.

For older drivers, crash rates are also correlated with hazard perception performance (Horswill et al. 2010; Horswill et al. 2015); however, these impairments stem from cognitive ageing, such as slower reaction times and restricted useful field of view (Horswill et al. 2008; Wetton et al. 2010). Compared with younger experienced drivers, older drivers often rate traffic scenes as more hazardous (Underwood et al. 2005) and have difficulty in detecting unexpected, peripheral or complex hazards (Bromberg et al. 2012; Romoser et al. 2013). As such, although they experience some difficulties with hazard detection, when made explicitly aware of hazards, older drivers' experience should help them appropriately appraise the risk posed.

\section{The Current Study}

Prior research demonstrates that driving safety differs as a function of environment and experience, which may relate to underlying differences in risk appraisal (Knight et al. 2013; Rakauskas et al. 2009). The current study was designed to assess factors that influence drivers' perceptions of risk versus safety, using a hazard rating task. Three attributes of the potential hazard were systematically manipulated: its environment; the object type; and its inherent safety risk. The environment manipulation tested whether participants rated rural environments as less hazardous than urban environments. The manipulation of inherent safety risk assessed discrepancies between objective and subjective risk. Finally, the object type manipulation assessed whether drivers perceive certain objects (e.g., cars vs. pedestrians) as fundamentally more hazardous or whether perceptions of hazardousness are contextdependent (e.g., varying more with environment and/or inherent safety risk).

It was hypothesised that hazard ratings would differ between urban and rural environments, with rural being rated less hazardous, and that hazard ratings would positively correlate with both driver age and general driving-related risk perception. 


\section{METHOD}

\section{Participants}

Participants were 63 licensed drivers (34 female, 29 male): 21 young drivers (18-24 years); 21 experienced drivers (25-40 years); and 21 older drivers (55-70 years). Participants were recruited through on-campus fliers, an online participant recruitment system, and the University of the Third Age. All participants drove at least weekly, had normal or corrected-to-normal visual acuity, and were compensated AUD\$10. Ethical aspects of the research were approved by the Australian National University Human Research Ethics Committee (protocol 2014/458).

\section{Apparatus}

Stimuli were presented on a 22” monitor. Viewing distance was approximately $55 \mathrm{~cm}$. Stimulus presentation and data acquisition were controlled via Qualtrics.

\section{Materials and Procedure}

Sessions were conducted individually in a quiet room with a researcher present. Participants provided informed consent before completing a computer-based questionnaire, which captured demographic and driving information (age, experience, exposure, crash history), followed by the hazard rating and risk perception tasks. Tasks were untimed, with an average completion time of 45 minutes.

Hazard Rating Task. Participants were presented with 100 pairs of side-by-side images, which differed in one detail. This change was circled and described (see Figure 1), so the task required hazard assessment but deliberately did not assess hazard detection. ${ }^{1}$ Participants rated the hazardousness of each change on an 11-point scale from 0 (not at all safety relevant) to 10 (highly safety relevant). Higher scores reflect higher perceived risk/hazardousness. Images were photographed from the driver's perspective on nearby urban and rural roads to ensure locations depicted were familiar, as previous research suggests familiarity impacts behaviour (e.g. Charlton and Starkey 2013; Harms and Brookhuis 2016; Martens and Fox 2007).

The stimulus set comprised 50 urban and 50 rural scenes. Trial order was randomised to avoid question order bias (Perreault 1976). Within each driving environment, changes occurred to one of five objects, with 10 trials per object. Urban changes involved a road sign, car, motorcycle, pedestrian, or traffic light. Rural changes involved a road sign, car, motorcycle, animal, or tree. From an experimental design perspective, it would be preferable to use the same objects in both environments; however, this was unfeasible as some common urban objects are unusual in rural environments and vice-versa. For the three objects that occurred in both urban and rural environments (signs, cars, motorcycles) changes were matched to ensure these categories were equivalent across environments.

Within each object category, half the images depicted a change with high inherent safety risk and half had low inherent safety risk (see Table 1). The fundamental difference between high- and low-risk changes was that high-risk changes would require a change to driver behaviour, whereas low-risk should not influence behaviour.

Risk Perception. Two driving-related risk perception measures were included. The relative crash risk measure asked participants to rate their crash risk compared with an average driver of the same age and gender, on a 5-point scale from 1 (very low) to 5 (very high; Gosselin et al. 2010). Nine scenarios were rated: tired; night; bad

\footnotetext{
${ }^{1}$ A version of these stimuli, without the change highlighted, has also been used to assess change blindness; for details see Beanland et al. (2017).
} 
weather; busy highway; changing lanes on a busy highway; windy road; yielding; crossing a visually cluttered intersection; and reacting to other drivers' unexpected manoeuvres.

The perceived risk of aberrant driving behaviours measure asked participants to rate the riskiness of 22 aberrant driving behaviours on a 5-point scale from 1 (not at all risky) to 5 (extremely risky). The list was adapted from previous risk perception questionnaires (Harbeck and Glendon 2013; Ivers et al. 2009) and included speeding, rule violations, and driving while distracted, fatigued or intoxicated.

\section{Data Analysis}

Data were analysed in SPSS using mixed within-between subjects analysis of variance (ANOVA). Bonferroni corrections were used to adjust for multiple comparisons and Greenhouse-Geisser corrections were applied where Mauchly's test revealed that the assumption of sphericity was violated. Separate analyses were conducted for urban and rural environments, as four object types appeared in only one environment (urban: pedestrians, traffic lights; rural: animals, trees). Following this, another analysis was conducted directly comparing urban and rural environments, including only ratings for objects that appeared in both environments (signs, cars, motorcycles).

\section{RESULTS}

\section{Participant Demographics}

Table 2 presents participants' demographic information. Age and driving experience were significantly correlated, $r(63)=.987, p<.001$. Age groups did not differ in age of first licensure or frequency of driving on urban or rural roads, but differed in weekly driving exposure. Young drivers drove significantly less than experienced drivers, whereas older drivers' habits were not significantly different to either younger group. All groups reported driving more frequently on urban versus rural roads, but there was no association between driving frequency and hazard rating scores for either environment (urban: $r(63)=.01, p=.925$; rural: $r(63)=-.06, p=.638$ ).

\section{Risk Perception}

Two risk perception scores were analysed: relative crash risk and perceived risk of aberrant driving behaviours. Item scores for each scale were averaged to derive an overall score, with higher scores indicating higher perceived risk. Cronbach's alpha $(\alpha)$ indicated good internal reliability for both scales (relative crash risk: $\alpha=.83$; perceived risk of aberrant driving behaviour: $\alpha=.86$ ).

Relative crash risk was not significantly associated with driver age or experience (see Table 2), and was not significantly correlated with hazard ratings for either urban, $r(63)=.07, p=.600$, or rural scenes, $r(63)=.05, p=$ .677. In contrast, perceived risk of aberrant driving behaviours was moderately positively correlated with average scores on the hazard rating task for both urban, $r(63)=.34, p=.007$, and rural scenes, $r(63)=.38, p=.002$. Perceived risk of aberrant driving behaviours was also correlated with driver age, $r(63)=.41, p=.001$ (see Table 2) and experience, $r(63)=.40, p=.001$, although age did not predict hazard rating scores.

\section{Urban Hazards}

Hazard ratings for urban scenes were analysed using mixed ANOVA with Driver Age as a betweensubjects factor and Change Object (road signs, cars, motorcycles, pedestrians, traffic lights) and Inherent Safety Risk 
(low, high) as within-subjects factors. Age did not have a significant main effect, $F(2,60)=0.09, p=.918$, and did not significantly interact with other variables (all $F<1.1, p>.43$ ).

There were significant main effects of Inherent Safety Risk, $F(1,60)=220.51, p<.001, \eta_{p}^{2}=.79$, and Object, $F(4,240)=33.07, p<.001, \eta_{p}^{2}=.36$. Participants rated low-risk changes as less hazardous $(M=3.0, S E=$ 0.3 ) than high-risk changes $(M=5.4, S E=0.2)$. Changes involving pedestrians were rated as significantly more hazardous than all other objects, and changes involving traffic lights were rated as more hazardous than changes involving signs or motorcycles, but not cars. There was also a significant Object $\times$ Inherent Safety Risk interaction, $F(2.8,166.8)=24.78, p<.001, \eta_{p}^{2}=.29$, see Figure 2. Post-hoc tests found the effect of Inherent Safety Risk was statistically significant for all objects but varied in magnitude, being largest for cars and smallest for signs (see Table 3).

\section{Rural Hazards}

Hazard ratings for rural scenes were analysed using mixed ANOVA with Driver Age, Change Object (road signs, cars, motorcycles, animals, trees) and Inherent Safety Risk as factors. Age did not have a significant main effect, $F(2,60)<0.01, p=.997$, and did not significantly interact with other variables (all $F<1, p>.53$ ).

There were significant main effects of Inherent Safety Risk, $F(1,60)=234.00, p<.001, \eta_{p}^{2}=.80$, and Object, $F(2.5,152.78)=116.58, p<.001, \eta_{p}^{2}=.66$. Participants rated low-risk changes as less hazardous $(M=$ 2.5, $S E=0.2)$ than high-risk changes $(M=4.3, S E=0.2)$. Changes involving animals $(M=6.0, S E=0.2)$ were rated as significantly more hazardous than all other types of changes, whereas trees $(M=0.8, S E=0.2)$ were rated less hazardous than all other objects. Changes involving cars $(M=3.0, S E=0.3)$ were rated as more hazardous than trees, but less hazardous than signs $(M=3.9, S E=0.3)$ or motorcycles $(M=3.6, S E=0.3)$. However, there was also a significant Object $\times$ Inherent Safety Risk interaction, $F(2.9,171.0)=143.09, p<.001, \eta_{p}^{2}=.71$, shown in Figure 2. Post-hoc tests revealed the effect of Inherent Safety Risk was largest for animals, and was not statistically significant for signs (see Table 3).

\section{Urban/Rural Comparison}

Hazard ratings were compared between urban and rural environments using within-subjects ANOVA with Environment (urban, rural), Change Object (road sign, car, motorcycle) and Inherent Safety Risk as factors.

There was a significant main effect of Environment, $F(1,63)=15.55, p<.001, \eta_{p}^{2}=.20$. Hazard ratings were significantly higher for changes in urban $(M=3.8, S E=0.2)$ compared with rural environments $(M=3.5, S E$ $=0.3)$. The main effect of Object was not significant, $F(1.6,96.6)=1.40, p=.251$, but there was a significant effect of Inherent Safety Risk, $F(1,62)=124.80, p<.001, \eta_{p}^{2}=.67$. Consistent with the separate analyses for urban and rural trials, participants gave higher hazard ratings to high-risk $(M=4.3, S E=0.3)$ compared with lowrisk changes $(M=2.9, S E=0.3)$.

A significant Environment $\times$ Inherent Safety Risk interaction, $F(1,62)=114.57, p<.001, \eta_{p}^{2}=.65$, revealed that the effect of Inherent Safety Risk was twice as large in urban $\left(M_{\text {diff }}=1.98\right)$ compared with rural environments $\left(M_{\text {diff }}=0.77\right)$. There was also a significant Environment $\times$ Object interaction, $F(2,124)=31.29, p<$ $.001, \eta_{p}^{2}=.34$. In urban environments, changes involving cars were rated as most hazardous and signs as least 
hazardous, whereas in rural environments, the opposite occurred. There was also a significant two-way Object $\times$ Inherent Safety Risk interaction, $F(1.3,82.75)=31.43, p<.001, \eta_{p}^{2}=.34$, and a significant three-way interaction, $F(2,124)=10.23, p<.001, \eta_{p}^{2}=.14$. The effect of Inherent Safety Risk was largest for cars, especially in urban environments, and smallest for road signs.

\section{DISCUSSION}

We hypothesised that hazard ratings for environmental changes, which we used as an operational measure of risk perception, would vary as a function of environment, age and driving-related risk perception. Although there was no effect of age on hazard ratings, the other hypotheses were supported. Hazard ratings also differed according to the type of object changed and its inherent safety risk (i.e., objective risk posed).

Consistent with previous research (Knight et al. 2013; Rakauskas et al. 2009; Streff and Geller 1988; Wilde 1998), participants rated changes as more hazardous in urban compared with rural environments. In particular, "high-risk" changes, such as changing speed limits or a vehicle appearing immediately ahead, were perceived as relatively more hazardous on urban roads. This suggests that the greater complexity of urban environments makes drivers more sensitive to nearby road users or changes in travel speed. Interestingly, our sample reported more frequent experience driving in urban versus rural areas. This is important as environmental familiarity influences risk perception: after repeated exposure to the same road, drivers make shorter glances towards roadside objects and increase travel speeds (Martens and Fox 2007). If familiarity were influencing the results, drivers should report lower risks in urban environments, but the opposite trend occurred, suggesting a robust effect whereby drivers perceive rural roads as less hazardous than urban roads.

The manipulation of inherent safety risk was included as subjective risk perception is not always aligned with the objective threat posed (Charlton et al. 2014). Although there was an overall effect of inherent safety risk, with participants generally rating high-risk changes as more hazardous than low-risk changes, the magnitude of this effect varied between objects. The largest effect was for animals by the roadside (high-risk) compared with in a paddock (low-risk). This reflects a genuine likely danger for participants, as the study region has the nation's highest rate of animal crashes (AAMI 2015). It is also consistent with Borowsky and Oron-Gilad's (2013) findings that hazard ratings correlate with the likely severity of resulting crashes, as animal crashes are likely to be severe in Australia (the most common target being kangaroos, which can appear suddenly on high speed roads). On the other

hand, participants showed relatively little sensitivity to the presence or position of trees by the roadside, even though trees are a common collision target (Wolf and Bratton 2006). Most strikingly, objective safety impact had no effect on participants' hazard ratings of rural road signs (and a relatively small effect for urban road signs), with participants rating a $10 \mathrm{~km} / \mathrm{h}$ change in speed limit as having equivalent safety relevance to minor semantic changes on an advisory sign. This suggests that drivers fail to appreciate the added risk that accompanies a $10 \mathrm{~km} / \mathrm{h}$ increase in speed, especially on rural roads.

Hazard ratings for changes in the environment were correlated with general driving-related risk perception, specifically participants' ratings of the riskiness of aberrant behaviours such as speeding, rule violations, and distracted driving, suggesting that hazard ratings are partially influenced by underlying individual differences in risk sensitivity (Sjöberg 2000). Conversely, hazard ratings were not associated with driver age. This may seem 
inconsistent with studies demonstrating age differences in hazard perception (Borowsky et al. 2009, 2010; Crundall et al. 2012; Finn and Bragg 1986; Horswill et al. 2008; Lee et al. 2008). However, not all hazard perception tasks reveal age- or experience-related differences (Chapman and Underwood 1998; Crundall et al. 2003; Sagberg and Bjørnskau 2006; Underwood et al. 2013). The reason for this is unclear, but one suggestion is that different hazard perception tasks tap different cognitive mechanisms. The current study required assessment of hazards, rather than identification, anticipation, or response towards hazards. Thus, the results suggest that when participants are made explicitly aware of potential hazards, their assessment of those hazards is influenced more by individual differences in risk sensitivity, rather than experience. In addition, our younger participants were most likely to have had a recent crash, which could have increased their driving-related risk sensitivity.

\section{Future Directions}

The current study provided valuable insights into factors that influence drivers' risk perception; however, there are some limitations. Most notably, participants were less familiar with rural roads than urban roads. This highlights a dilemma for researchers comparing behaviour in different environments: within-subjects comparisons will likely involve participants being more familiar with one environment, whereas between-subjects comparisons introduce other potential confounds. Encouragingly, our results were broadly consistent with previous research, which suggests there are robust differences in drivers' risk appraisals between rural and urban roads. The findings would also impact further reviews on GLS in Australia, by suggesting more emphasis on risk perception across urban and rural environments, as opposed to emphasising on age and licensure status.

Another limitation is that we did not assess response time. Future research could assess whether response time varies systematically with environmental features. Faster responses would indicate that assessment is relatively, whereas longer response times reflect greater deliberation. Alternatively, future research could restrict display time to simulate the rapid judgements drivers routinely make, which may also be more sensitive to effects of driver age.

It is also important to note that the study scope is relatively small, based on drivers in the Canberra region. Given its computerised format, future research could expand the study scope by recruiting participants online in order to generalise the findings to other populations.

\section{Conclusions}

The current study investigated the effects of driving environment, driver age and risk sensitivity on assessment of risk in driving scenes. The results demonstrate that drivers perceive rural roads as less risky than urban roads, even when similar scenarios occur. Age did not affect hazard ratings, suggesting that age and experience do not affect assessment of explicitly-revealed hazards. Rather, participants' assessment of risk was influenced more by individual differences in risk sensitivity. However, drivers overall failed to appreciate the inherent hazards in some situations, such as changing speeds on rural roads. This highlights the need for driver education to emphasise not just hazard detection, but also appraisal of the hazard's risk and relevance, to promote road safety. 


\section{REFERENCES}

AAMI. Animal collisions on the rise in winter months. 2015. Available at: https://www.aami.com.au/mediacentre/act-animal-collisions-rise-winter-months.html. Accessed September 27, 2016.

Beirness DJ. Do we really drive as we live? The role of personality factors in road crashes. Alcohol Drugs Driving. 1993;9(3-4):129-143.

Beanland V, Filtness AJ, Jeans R. Change detection in urban and rural driving scenes: Effects of target type and safety relevance on change blindness. Accid Anal Prev. 2017;100C:111-122.

Benda HV, Hoyos CG. Estimating hazards in traffic situations. Accid Anal Prev. 1983;15(1):1-9.

Borowsky A, Oron-Gilad T. Exploring the effects of driving experience on hazard awareness and risk perception via real-time hazard identification, hazard classification, and rating tasks. Accid Anal Prev. 2013;59:548-565.

Borowsky A, Oron-Gilad T, Parmet Y. Age and skill differences in classifying hazardous traffic scenes. Transp Res Part F Traffic Psychol Behav. 2009;12(4):277-287.

Borowsky A, Shinar D, Oron-Gilad T. Age, skill, and hazard perception in driving. Accid Anal Prev. 2010;42(4):1240-1249.

Boufous S, Ivers R, Senserrick T, Stevenson M. Attempts at the practical on-road driving test and the hazard perception test and the risk of traffic crashes in young drivers. Traffic Inj Prev. 2011;12(5);475-482.

Bromberg S, Oron-Gilad T, Ronen A, Borowsky A, Parmet Y. The perception of pedestrians from the perspective of elderly experienced and experienced drivers. Accid Anal Prev. 2012;44(1):48-55.

BITRE (Bureau of Infrastructure, Transport and Regional Economics). Road trauma Australia, 2015 statistical summary. Canberra, Australia: BITRE; 2016.

Chapman PR, Underwood G. Visual search of driving situations: Danger and experience. Perception. 1998;27(8):951-964.

Charlton SG, Starkey NJ. Driving on familiar roads: Automaticity and inattention blindness. Transp Res Part F Traffic Psychol Behav. 2013;19:121-133.

Charlton SG, Starkey NJ, Perrone JA, Isler RB. What's the risk? A comparison of actual and perceived driving risk. Transp Res Part F Traffic Psychol Behav. 2014;25:50-64.

Crundall D, Andrews B, van Loon E, Chapman P. Commentary training improves responsiveness to hazards in a driving simulator. Accid Anal Prev. 2010;42:2117-2124.

Crundall D, Chapman P, Trawley S, Collins L, van Loon E, Andrews B, Underwood G. Some hazards are more attractive than others: Drivers of varying experience respond differently to different types of hazard. Accid Anal Prev. 2012;45:600-609.

Crundall D, Chapman P, Phelps N, Underwood G. Eye movements and hazard perception in police pursuit and emergency response driving. J Exp Psychol Appl. 2003;9(3):163-174.

Crundall DE, Underwood G. Effects of experience and processing demands on visual information acquisition in drivers. Ergonomics. 1998;41(4):448-458.

Dunsire M, Baldwin S. Urban-rural comparisons of drink-driving behavior among late teens: A preliminary investigation. Alcohol Alcohol. 1999;34(1):59-64. 
Eiksund S. A geographical perspective on driving attitudes and behaviour among young adults in urban and rural Norway. Saf Sci. 2009;47(4):529-536.

Elander J, West R, French D. Behavioral correlates of individual differences in road-traffic crash risk: An examination of methods and findings. Psychol Bull. 1993;113(2):279-294.

Finn P, Bragg BWE. Perception of the risk of an accident by young and older drivers. Accid Anal Prev. 1986;18:289-298.

Fisher DL, Laurie NE, Glaser R, Connerney K, Pollatsek A, Duffy SA, Brock J. Use of a fixed-base driving simulator to evaluate the effects of experience and PC-based risk awareness training on drivers' decisions. Hum Factors. 2002;44:287-302.

Gill GK. Perception of safety, safety violation and improvement of safety in aviation: Findings of a pilot study. J Air Transp. 2004;9(3):45-55.

Gosselin D, Gagnon S, Stinchcombe A, Joanisse M. Comparative optimism among drivers: An intergenerational portrait. Accid Anal Prev. 2010;42(2):734-740.

Harbeck EL, Glendon AI. How reinforcement sensitivity and perceived risk influence young drivers’ reported engagement in risky driving behaviors. Accid Anal Prev.2013;54:73-80.

Harms IM, Brookhuis KA. Dynamic traffic management on a familiar road: Failing to detect changes in variable speed limits. Transp Res Part F Traffic Psychol Behav. 2016;38:37-46.

Horswill MS, Anstey KJ, Hatherly CG, Wood, JM. The crash involvement of older drivers is associated with their hazard perception latencies. J Int Neuropsychol Soc. 2010;16(5):939-944.

Horswill MS, Hill A, Wetton M. Can a video-based hazard perception test used for driver licensing predict crash involvement? Accid Anal Prev. 2015;82:213-219.

Horswill M, Marrington S, McCullough C, Wood J, Pachana N, McWilliam J, Raikos M. The hazard perception ability of older drivers. J Gerontol B Psychol Sci Soc Sci. 2008;63(4):212-218.

Ivers R, Senserrick T, Boufous S, Stevenson M, Chen HY, Woodward M, Norton R. Novice drivers' risky driving behavior, risk perception, and crash risk: Findings from the DRIVE study. Am J Public Health. 2009;99(9):1638-1644.

Kington R, Reuben D, Rogowski J, Lillard L. Sociodemographic and health factors in driving patterns after 50 years of age. Am J Public Health. 1994;84(8):1327-1329.

Knight PJ, Iverson D, Harris MF. The perceptions of young rural drivers in NSW, Australia of speeding and associated risk: A mixed methods study. Accid Anal Prev. 2013;55:172-177.

Leadbeater BJ, Foran K, Grove-White A. How much can you drink before driving? The influence of riding and impaired adults and peers on the driving behaviors of urban and rural youth. Addiction. 2008;103(4):629-637.

Lee SE, Klauer SG, Olsen EC, Simons-Morton BG, Dingus TA, Ramsey DJ, Ouimet MC. Detection of road hazards by novice teen and experienced adult drivers. Transp Res Rec. 2008;2078:26-32.

Lowrance WW. Of acceptable risk: Science and the determination of safety. Los Altos, CA: William Kaufmann; 1976. 
Machado-León JL, de Oña J, de Oña R, Eboli L, Mazzulla G. Socio-economic and driving experience factors affecting drivers’ perceptions of traffic crash risk. Transp Res Part F Traffic Psychol Behav. 2016;37:41-51.

Martens MH, Fox MRJ. Do familiarity and expectations change perception? Drivers' glances and response to changes. Transp Res Part F Traffic Psychol Behav. 2007;10(6):476-492.

Mayhew DR, Simpson HM, Pak A. Changes in collision rates among novice drivers during the first months of driving. Accid Anal Prev. 2003;35:683-691.

McKenna FP, Horswill MS, Alexander JL. Does anticipation training affect drivers' risk taking? J Exp Psychol Appl. 2006;12:1-10.

NHTSA (National Highway Traffic Safety Administration). Traffic Safety Facts 2010: A compilation of motor vehicle crash data from fatality analysis reporting system and the general estimates system. 2010. Available at: http://www-nrd.nhtsa.dot.gov/Pubs/811659.pdf. Accessed September 27, 2016.

Nordjærn T, Jörgensen SH, Rundmo T. An investigation of driver attitudes and behaviour in rural and urban areas in Norway. Saf Sci. 2010;48:348-356.

Perreault WD. Controlling order-effect bias. Public Opin Q. 1975;39(4):554-551.

Rakauskas ME, Ward NJ, Gerberich SG. Identification of differences between rural and urban safety cultures. Accid Anal Prev. 2009;41:931-937.

Romoser MRE, Pollatsek A, Fisher DL, Williams CC. Comparing the glance patterns of older versus younger experienced drivers: Scanning for hazards while approaching and entering the intersection. Transp Res Part F Traffic Psychol Behav. 2013;16:104-116.

Sagberg F, Bjørnskau T. Hazard perception and driving experience among novice drivers. Accid Anal Prev. 2006;38(2):407-414.

Siskind V, Steinhardt D, Sheehan M, O’Connor T, Hanks H. Risk factors for fatal crashes in rural Australia. Accid Anal Prev. 2011;43(3):1082-1088.

Sjöberg L. Factors in risk perception. Risk Anal. 2000;20(1):1-12.

Streff FM, Geller ES. An experimental test of risk compensation: Between-subject versus within-subject analyses. Accid Anal Prev. 1988;20(4):277-287.

Thiffault P, Bergeron J. Monotony of road environment and driver fatigue: a simulator study. Accid Anal Prev. 2003;35(3):381-391.

Underwood G, Ngai A, Underwood J. Driving experience and situation awareness in hazard detection. Saf Sci. 2013;56:29-35.

Underwood G, Phelps N, Wright C, van Loon E, Galpin A. Eye fixations scanpaths of younger and older drivers in a hazard perception task. Ophthalmic Physiol Opt. 2005;25(4):346-356.

Vivoli R, Bergomi M, Rovesti S, Brussetti P, Guaitoli GM. Biological and behavioural factors affecting driving safety. J Prev Med Hygiene. 2006;47:69-73.

Wang Y, Zhang W, Salvendy G. Effects of a simulation-based training intervention on novice drivers' hazard handling performance. Traffic Inj Prev. 2010;11:16-24. 
Wetton MA, Horswill MS, Hatherly C, Wood JM, Pachana NA, Anstey KJ. The development and validation of two complementary measures of drivers’ hazard perception ability. Accid Anal Prev. 2010;42(4):1232-1239.

WHO (World Health Organization). Global Status Report on Road Safety 2015. Geneva, Switzerland: WHO; 2015. Wilde GJS. Risk homeostasis theory: An overview. Inj Prev. 1988;4:89-91.

Williams AF. Teenage drivers: Patterns of risk. J Saf Res. 2003;34(1):5-15.

Wolf KL, Bratton N. Urban trees and traffic safety: Considering US roadside policy and crash data. Arboric Urban For. 2006;32(4):170-179. 
Table 1

Examples of scene changes with high and low inherent safety risk

\begin{tabular}{|c|c|c|c|}
\hline Changed Object & Environment & Low Inherent safety risk & High Inherent safety risk \\
\hline Car & Rural, Urban & $\begin{array}{l}\text { Car parked, on other side of divided } \\
\text { road, or very far ahead }\end{array}$ & $\begin{array}{l}\text { Car immediately in front, or } \\
\text { oncoming on undivided road }\end{array}$ \\
\hline Motorcycle & Rural, Urban & $\begin{array}{l}\text { Motorcycle on other side of divided } \\
\text { road, or very far ahead }\end{array}$ & $\begin{array}{l}\text { Motorcycle immediately in front, or } \\
\text { oncoming on undivided road }\end{array}$ \\
\hline Road Sign & Rural, Urban & $\begin{array}{l}\text { Advisory sign changed (but content } \\
\text { remains semantically similar) }\end{array}$ & Speed limit changed $( \pm 10 \mathrm{~km} / \mathrm{h})$ \\
\hline Animal & Rural & Kangaroo or cow in paddock & Kangaroo by roadside \\
\hline Tree & Rural & Tree in paddock & Tree by roadside \\
\hline Traffic Light & Urban & $\begin{array}{l}\text { Added turn arrow (e.g., from red } \\
\text { light to red with red arrow, or from } \\
\text { green light to green with green } \\
\text { arrow) }\end{array}$ & $\begin{array}{l}\text { All lights change colour (e.g., } \\
\text { green/orange, red/green, } \\
\text { orange/red) }\end{array}$ \\
\hline Pedestrian & Urban & $\begin{array}{l}\text { Pedestrian waiting at traffic lights } \\
\text { or bus stop }\end{array}$ & $\begin{array}{l}\text { Pedestrian crossing illegally or } \\
\text { about to cross illegally on busy road }\end{array}$ \\
\hline
\end{tabular}


RISK PERCEPTION ON URBAN AND RURAL ROADS

Table 2

Participant demographics by age group

\begin{tabular}{|c|c|c|c|c|}
\hline & $\begin{array}{l}\text { Young Drivers } \\
\text { (18-24 years) }\end{array}$ & $\begin{array}{c}\text { Experienced } \\
\text { Drivers } \\
\text { (25-40 years) }\end{array}$ & $\begin{array}{l}\text { Older Drivers } \\
\text { (55-70 years) }\end{array}$ & Comparison \\
\hline Mean age & $20.6(1.3)$ & $29.1(3.6)$ & $62.5(4.8)$ & $F(2,60)=818.94, p<.001, \eta_{p}^{2}=.97$ \\
\hline $\begin{array}{l}\text { Years of driving } \\
\text { experience }\end{array}$ & $2.8(1.7)$ & $9.7(3.7)$ & $43.3(6.0)$ & $F(2,60)=558.76, p<.001, \eta_{p}^{2}=.95$ \\
\hline Age of first licensure & $17.8(1.2)$ & $19.4(2.5)$ & $19.2(4.3)$ & $F(2,60)=1.81, p=.173, \eta_{p}^{2}=.06$ \\
\hline Hours driven per week & $6.5(6.5)$ & $14.2(13.4)$ & $7.2(7.8)$ & $F(2,60)=4.03, p=.023, \eta_{p}^{2}=.12$ \\
\hline $\begin{array}{l}\text { Kilometres driven per } \\
\text { week }\end{array}$ & $132(137)$ & $294(233)$ & $231(143)$ & $F(2,60)=4.47, p=.015, \eta_{p}^{2}=.13$ \\
\hline \multicolumn{5}{|l|}{ Driving frequency: } \\
\hline Urban roads & $\begin{array}{l}38 \% \text { daily } \\
62 \% \text { weekly }\end{array}$ & $\begin{array}{l}76 \% \text { daily } \\
24 \% \text { weekly }\end{array}$ & $\begin{array}{l}71 \% \text { daily } \\
29 \% \text { weekly }\end{array}$ & $\chi^{2}(2)=7.55, p=.023$ \\
\hline Rural roads & $\begin{array}{c}0 \% \text { daily } \\
10 \% \text { weekly } \\
29 \% \text { monthly } \\
52 \% \text { less than } \\
\text { monthly } \\
10 \% \text { never }\end{array}$ & $\begin{array}{c}10 \% \text { daily } \\
14 \% \text { weekly } \\
43 \% \text { monthly } \\
19 \% \text { less than } \\
\text { monthly } \\
14 \% \text { never }\end{array}$ & $\begin{array}{c}0 \% \text { daily } \\
19 \% \text { weekly } \\
38 \% \text { monthly } \\
43 \% \text { less than } \\
\text { monthly } \\
0 \% \text { never }\end{array}$ & $\chi^{2}(2)=3.14, p=.208$ \\
\hline $\begin{array}{l}\text { Drivers reporting at } \\
\text { least one crash in past } \\
12 \text { months }\end{array}$ & $38 \%$ & $0 \%$ & $19 \%$ & $\chi^{2}(2)=9.88, p=.007$ \\
\hline $\begin{array}{l}\text { Perceived risk of } \\
\text { aberrant driving } \\
\text { behaviours }\end{array}$ & $3.9(0.4)$ & $3.9(0.4)$ & $4.2(0.3)$ & $F(2,60)=5.03, p=.010, \eta_{p}^{2}=.14$ \\
\hline $\begin{array}{l}\text { Relative crash risk } \\
\text { (compared to driver of } \\
\text { same age and gender) }\end{array}$ & $2.8(0.5)$ & $2.8(0.5)$ & $2.7(0.4)$ & $F(2,60)=0.02, p=.979, \eta_{p}^{2}=.00$ \\
\hline
\end{tabular}

Note. Percentages have been rounded to integers and may not sum to $100 \%$. Driving frequency is recorded as

“daily” if participants reported daily driving frequency; "weekly” if they reported driving between 1-5 times per week; "monthly" if they reported driving 1-3 times per month. 
Table 3

Pairwise comparisons for participants' hazard ratings for changes with high and low inherent safety risk, by type of changed object and driving environment

\begin{tabular}{llll}
\hline Environment & Changed Object & $\begin{array}{c}\text { Mean (SD) Difference: } \\
\text { High }- \text { Low impact changes }\end{array}$ & Statistical Significance \\
\hline Urban & Road Sign & $1.1(2.2)^{* * *}$ & $t(62)=3.92, p<.001, d=0.49$ \\
& Car & $3.3(1.5)^{* * *}$ & $t(62)=18.00, p<.001, d=2.27$ \\
& Motorcycle & $1.6(1.6)^{* * *}$ & $t(62)=7.95, p<.001, d=1.00$ \\
& Pedestrian & $2.9(1.8)^{* * *}$ & $t(62)=13.18, p<.001, d=1.66$ \\
& Traffic Light & $2.9(2.2)^{* * *}$ & $t(62)=10.51, p<.001, d=1.32$ \\
\hline Rural & Road Sign & $0.0(1.9)^{*}$ & $t(62)=0.03, p=.979, d=0.00$ \\
& Car & $1.3(1.1)^{* * *}$ & $t(62)=9.27, p<.001, d=1.17$ \\
& Motorcycle & $1.0(1.4)^{* * *}$ & $t(62)=5.68, p<.001, d=0.72$ \\
& Animal & $6.2(2.7)^{* * *}$ & $t(62)=18.02, p<.001, d=2.27$ \\
& Tree & $0.5(0.9)^{* * *}$ & $t(62)=4.51, p<.001, d=0.57$
\end{tabular}




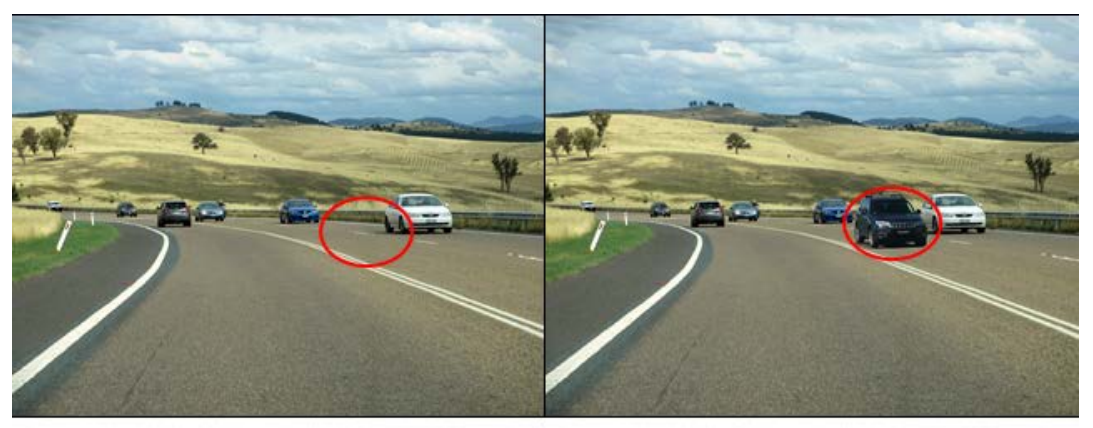

Car absent/present

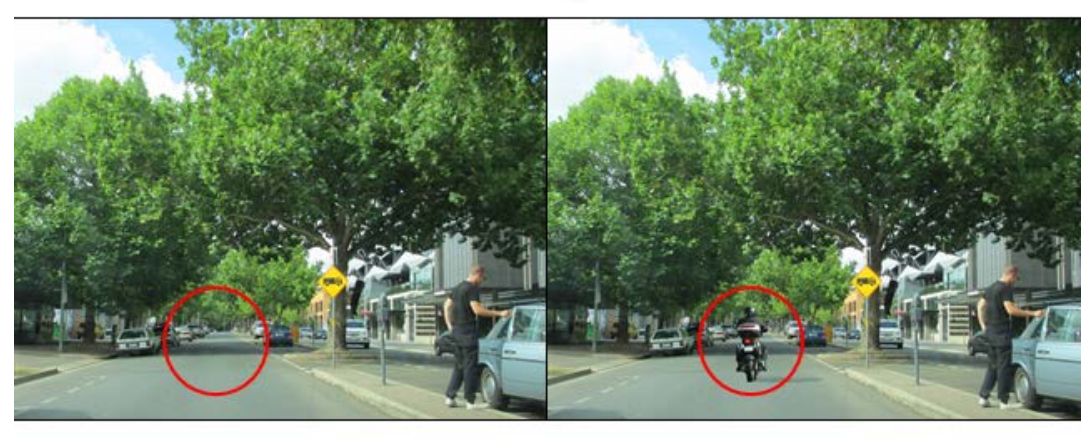

Motorcycle absent/present

Figure 1. Example stimuli from the safety rating task, depicting rural (upper panel) and urban (lower panel) driving environments. Participants were asked to rate the circled change on an 11-point scale of 0 (not at all safety relevant) to 10 (highly safety relevant). 


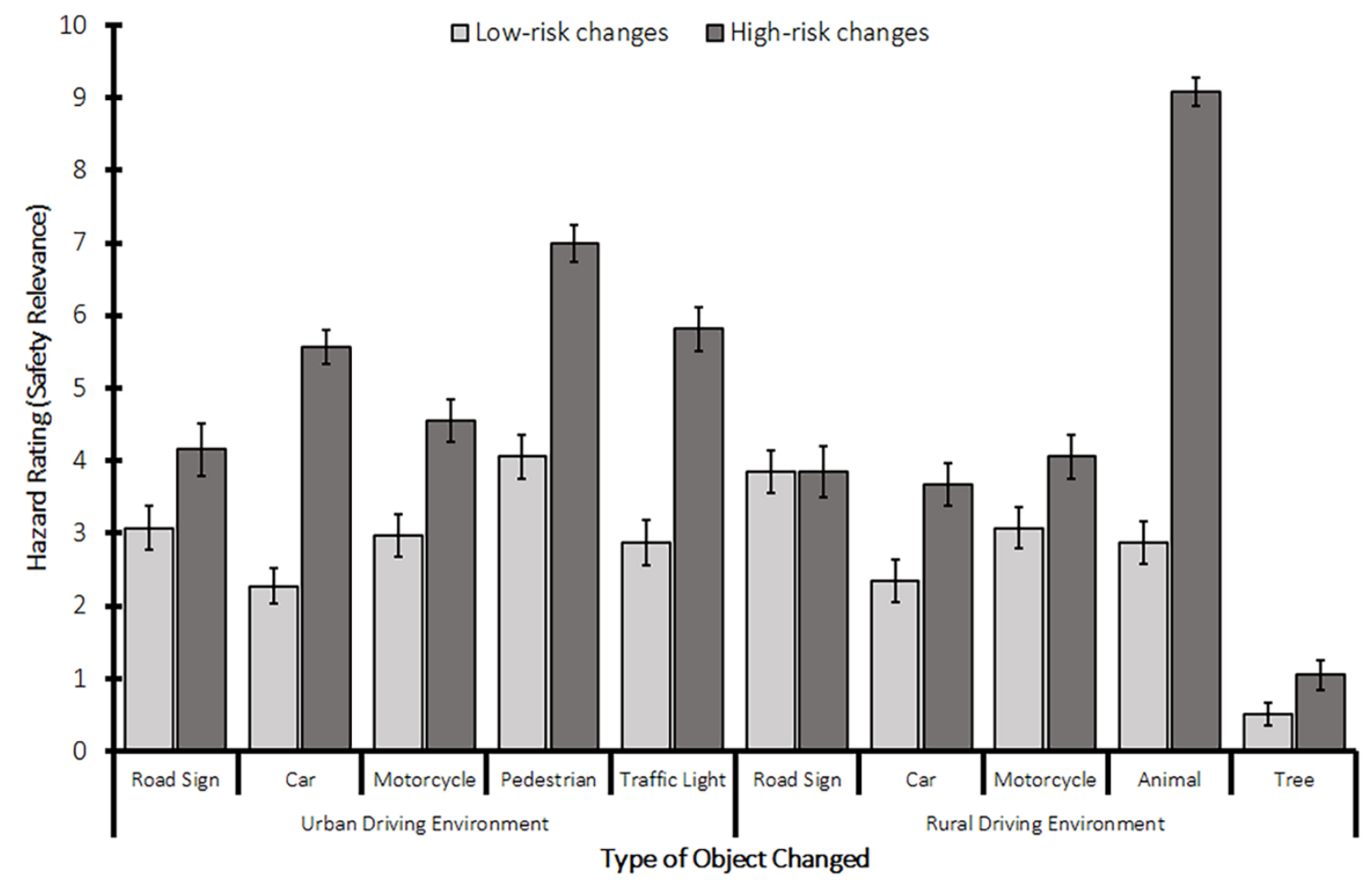

Figure 2. Average hazard ratings of changes in urban and rural driving environments, by change type and inherent safety risk. Possible scores on the hazard rating scale range from 0 (not at all safety relevant) to 10 (highly safety relevant). Error bars represent \pm 1 standard error. 